\title{
Notes on Operations The Big Picture: A Holistic View of E-book Acquisitions
}

\author{
Ronald M. Lewis and Marie R. Kennedy
}

The merging of two departments into the Acquisitions and Collection Development Department afforded Loyola Marymount University an opportunity to rethink existing workflows, with the acquisition of electronic books (e-books) being identified as a critical task to review. Process mapping was used to show the complexity of different tasks being performed in the department and to provide a visualization mechanism for staff to see how their work fit into a sequence of actions as part of a larger workflow. The authors listed the types of acquisition models used at their library for e-books and constructed process maps for the following six major types: 1. Firm order e-books; 2. Firm order e-book collections; 3 . Approval order e-books; 4. Demand-driven e-books; 5. Standing order e-books, and; 6. Subscription e-book database. The authors merged the individual process maps into a single visualization to view the entirety of the acquisition process as a whole and to show how the different e-book acquisition models relate and diverge from one another.

T $\mathrm{n}$ a highly technical environment, it can be easy to lose sight of how the task 1 with which one is charged with completing fits into or impacts the larger organization. When the head of Collection Development became the new head of Acquisitions and Serials, the two departments merged to become the Acquisitions and Collection Development Department at the William H. Hannon Library. In 2014, the newly combined departments had an opportunity to review existing workflows and determine the necessary staffing to complete particular tasks as a natural part of the reorganization process. The Acquisitions and Collection Development Department first identified critical workflows and focused on revising the procedural documentation for those essential tasks. One essential workflow that was identified was for acquiring electronic books (e-books). As the group met to discuss the workflow and identify the staff members that performed each function in the e-book acquisition process, it became clear that as staff completed their steps for inclusion in the integrated library system (ILS) and related commercial product systems, there was a feeling of unfamiliarity with the steps that other staff were performing, and a lack of knowledge regarding where or when the overall process began or ended. This lack of comprehension of the complete e-book acquisitions process is important to note, because in an electronic environment, as De Fino and Lo state, "There are no physical books to pass from one player to the next, and there is no trigger to activate each step of the workflow."1 The acquisitions librarian, in a newly created position, saw the reviewing and documenting of workflows as an opportunity to develop a mechanism to transition from a silo workflow mentality and show staff how their individual procedures incorporate into a full workflow process.

Before the two departments merged, the Acquisitions and Serials Department spent several years creating a wiki documenting step-by-step instructions for all tasks completed in the department, even those provided by student employees. Merging with another department provided the opportunity to rethink the wiki, which included a plan to institute a visualization of the key

steps for each procedure. The effort to document workflows with a visual process

Ronald M. Lewis (ronald.lewis@Imu .edu) is the Acquisitions Librarian at Loyola Marymount University. Marie R. Kennedy (marie.kennedy@lmu.edu) is the Serials and Electronic Resources Librarian at Loyola Marymount University.

Manuscript submitted March 17, 2017: returned to authors for revision July 31, 2018; revised manuscript submitted September 18, 2018; accepted for publication December 28, 2018. 
map was timely, as it allowed staff in the newly merged department to see evidence of the complexity of some of the tasks they completed, and how their own work fits into the entire process.

\section{Problem Statement}

During departmental conversations about reviewing existing workflows, e-books emerged as a top concern. Given the increasing amount of funds spent to purchase e-books, and the complexity of acquisition models, the department wanted to ensure that staff were working as efficiently as possible, and avoiding duplication of effort or missed steps in the process. Additionally, the authors were interested in learning how all of the e-book workflows possibly fit together to better understand the acquisitions process from a holistic viewpoint; the concept of process mapping was identified as a means by which the department could outline and visualize the whole process.

\section{Literature Review}

\section{Workflow}

E-books have been advantageous for patrons who require immediate access to content, yet providing timely access is challenging because of the multiple ways that e-books can be acquired. In their review of the professional literature, the authors did not find a universal approach to establishing workflow models for e-book acquisition due to the different types, sizes, and staffing of libraries. They examined the literature specifically to learn how libraries described workflows, lifecycles or stages, tools or systems, acquisition models, challenges, and solutions as they relate to e-books or electronic resource management.

Regarding the concept of workflow, there can be confusion about how policy, workflow, and procedure are defined and relate to one another. Mackinder noted the underlying differences between these types of documentation as "policy decisions determine the form a workflow will take, and the workflow should outline the guidelines to be followed in the procedures that pertain to it." In Mackinder's opinion, with which the authors agree, the terms used within a workflow should not refer to specific vendor-provided products because they change over time for various reasons, and the documentation should serve as a connection between the plan established in a policy and the exact steps to follow as detailed in the procedure. ${ }^{3}$ Rather than listing step-bystep instructions on how to perform a task, a workflow can provide the big picture and serve as a guide to illustrate for stakeholders the order in which actions are expected to be accomplished and why. Having a documented workflow can prevent a situation where a single staff member holds knowledge, particularly if that person leaves, retires, or is unexpectedly unavailable, such as in the case of an emergency or illness, and it provides assurance that the work will proceed without interruption if this person is not available. When reflecting on the biggest challenges of documenting a workflow, Mackinder conveyed that "balancing the big picture needs with providing enough context to allow staff to determine the next step; finding the best way to represent the myriad possibilities that exist for any given stop on the lifecycle road; and finding the time to devote to this project while still managing the very day-to-day tasks that I will be working to document."4

The literature reveals a variety of phases involved in the management of a library's e-resources, and an electronic resource management (ERM) system provides features to address these series of stages. When convening a task force of librarians and staff to examine how e-books were managed at their institution, Beisler and Kurt determined that four processes occurred in the workflow: assessment/ acquisition, access, maintenance/troubleshooting, and end of life. ${ }^{5}$ Vasileiou, Rowley, and Hartley reviewed the literature on e-books and did not find studies that offer "a holistic framework of the issues and challenges mapped onto the stages in the e-book management process," and semi-structured interviews were conducted with academic librarians to identify "the stages in the e-book management process and key activities and challenges and issues associated with each of the stages." ${ }^{\prime 6}$ Vasileiou, Rowley, and Hartley's research resulted in demonstrating the activities and challenges occurring within a framework for the management of e-books that consisted of nine stages: collection development policy; budget; discovery; evaluation and selection; license negotiations; cataloging and delivery; marketing/promotion and user education; monitoring and reviewing; and renewals and cancellations. ${ }^{7}$ Anderson believed that five elements required a dedicated focus to minimize the difficulty of managing e-resources: knowledge base, budget, administration, licensing, and reports. ${ }^{\circ}$ Depending on the ERM used and dedicated staff, the time and effort devoted to these five parts will differ by library. The stages or elements described above can be thought of as an e-resource's lifecycle. Mackinder envisioned each of the different stages of an e-resource lifecycle as containing workflows within workflows and its lifetime consisting of six phases: new acquisition, activation, cataloging, maintaining access, troubleshooting, and evaluation. ${ }^{9}$

The authors noted several tools cited in the literature used in libraries to assist in the management of an e-resource's lifecycle in libraries and the impact specific features and functions can have on workflows. Tull et al. outlined the steps of an ERM workflow and described how 
Innovative Interfaces, Inc.'s ERM could be used at each stage of the process. ${ }^{10}$ England, $\mathrm{Fu}$, and Miller maintained checklists to manage e-resources using LibGuides and provided steps on creating a checklist through planning, developing, drafting, testing, and validating. ${ }^{11}$ Dowdy and Raeford selected IBM's BlueWorks Live and Business Process Manager as its ERM system because it had the potential to revise their e-resources workflow to meet their needs, like minimizing the need for using email as a communication tool and recalling knowledge. ${ }^{12}$ Smith utilized the LibAnswers ticketing system to manage access issues commonly caused by vendor problems, subscription problems, incorrect metadata, local system problems, authentication problems, and end user problems; using a ticketing system eliminated the need for email because communication was provided in a centralized location. ${ }^{13}$ Chen, Kim, and Montgomery discussed the impact Ex Libris' Alma library services platform had on improving the overall efficiency in e-book record management, which allowed them to transition from a mostly manual process used with their previous system. ${ }^{14}$

Beisler and Kurt noted the lack of published material about e-book workflows and observed three initial paths for the acquisition of e-books before the models merged to provide access: database subscription/standing order, one-time purchase without annual fees, and one-time purchase with annual fees. ${ }^{15}$ Schmidt identified four e-book workflows based on acquisition models: title-by-title publisher direct purchases; vendor subscription packages; patron-driven acquisitions through a vendor; and purchased e-book collection from a publisher. ${ }^{16}$

The demand-driven acquisition (DDA) model removes the librarian from the selection process of a library's e-book collection and gives the patron control through discovery and use of a title. De Fino and Lo provided a case study of their institution's workflow when setting up a patron-driven plan, the results of their pilot project, and what they learned by using this type of collection development model. ${ }^{17} \mathrm{~A}$ DDA case study from Draper described the cataloging policies established at his institution for MARC records and how this was implemented, while also discussing the workflows employed by their staff to provide this new service for their patrons. ${ }^{18}$ Downey explained the rationale for starting a DDA pilot project at her institution, what steps were taken to set up this plan with a book jobber, and outlined the sequence of actions in the technical process workflow. ${ }^{19}$ Similarly, Vermeer also detailed the reasons her institution decided to trial DDA, the preparation involved in setting it up, and the adjustments made to the workflow from unexpected issues. ${ }^{20}$

Emery acknowledged the challenges of being unable to fully adapt procedures used for print material because it could not systematically transfer to its electronic counterpart due to the multiplicity of new variables to consider, such as accounting for the different ways an e-resource can be purchased and ensuring that it is set up properly to be accessible to patrons. ${ }^{21} \mathrm{Wu}$ and Mitchell looked at their use of vendor-provided e-book records and described how the batch processing of these records was managed at their institution. ${ }^{22}$ Although this offers the benefit of quickly making a large number of titles accessible to patrons, it also presents a challenge of handling records of varying quality from a multitude of vendors. Traill also discussed the steps taken at her institution to identify and address the most common issues discovered during an analysis of their vendor-supplied records. ${ }^{23} \mathrm{~A}$ further case study from Turner provided another examination of the benefits and challenges when using the batch loading process. ${ }^{24}$ Vasileiou, Rowley, and Hartley identified license negotiations, marketing/promotion and user education, usage evaluation and monitoring, and renewal and cancellation practices as the areas of the e-book management process that need the most development. ${ }^{25}$ Hodge, Manoff, and Watson presented the difficulties encountered in ensuring that all the steps for an individual e-book workflow were completed without repeating the same actions. ${ }^{26}$ Regarding e-book collections, Hodge et al. viewed access as the central challenge due to the steps necessary to prepare a large number of records for patrons. ${ }^{27}$ Since access issues are a common occurrence for e-resources, Samples and Healy conducted a survey of Association of Research Libraries (ARL) members in the US and Canada to learn how other institutions handle the troubleshooting aspect of e-resource management workflow, and discovered responses were mainly reactive and not well coordinated. ${ }^{28}$

Due to the complex nature of e-resource management, solutions or recommendations have been suggested within the profession to adjust a workflow that is less straightforward than that used for print materials. Emery believed that e-resources workflows could be streamlined with management tools developed to use three systematic processing approaches: transactional, knowledge management, and decision support. ${ }^{29}$ With the increased use of e-books at libraries, Vasileiou, Rowley, and Hartley recommended the following adjustments to a library's workflows, policies, and procedures: formulate policies for the development of e-book collections; develop consistent selection criteria and acquisition processes; build relationships with vendors to deal with an assortment of e-book related issues; develop marketing strategies; and monitor how patrons use e-books. ${ }^{30}$ 


\section{Process Mapping}

The authors also reviewed literature on how libraries have used process mapping to document these workflows. Watkins defined flowcharts, which can also be called process maps, as diagrammed illustrations of a process from initiation to completion that can be revised if a change occurs that affects the steps involved in the procedure. Five stages were identified in charting the flow of work: planning and conceptualizing, design, evaluate, documenting, and communication and reporting. ${ }^{31}$ Barbrow and Hartline defined process mapping as an exercise to visually describe the important details of a workflow-a finished process map shows the stakeholders responsible for the activities taking place; lays out the ideas, information, and data occurring at certain steps throughout the process; and provides a means for retaining institutional knowledge. ${ }^{32}$ They also viewed process mapping as a tool for organizational assessment because doing it routinely brings value to one's institution by evaluating processes to improve them.

Libraries have used process mapping as a planning and management tool in a variety of situations, including the management of electronic journal (e-journal) subscriptions to troubleshooting access issues. As a result of merging departments and the library's strategic mission, Watkins discussed a project to create a series of flowcharts illustrating the document delivery services workflow. ${ }^{33}$ Striving to improve a process that overwhelmed three separate units, Youngman evinced how process mapping improved the selection, ordering, and payment for print monographs. ${ }^{34}$ Yue and Anderson addressed using a flowchart from the Digital Library Federation Electronic Resource Management Initiative as a starting point to document the workflow involved in managing e-journal subscriptions. ${ }^{35}$ When starting in a newly created position, Leffler developed a flowchart as a first step to defining her responsibilities because it visually showed the complexity of managing e-resources to staff who were unfamiliar with this lifecycle. ${ }^{36}$ Using the business process modeling technique, role activity diagram, Tbaishat examined print and e-journal acquisition at two academic libraries, compared the workflows, and discussed the differences with each library staff member for possible improvements to their process. ${ }^{37}$ Prilop, Westbrook, and German discussed a project at the University of Houston Libraries to develop an interdepartmental workflow for the digitization of materials in a central, online depository and provided the steps taken to collaboratively create this process map. ${ }^{38}$ Hamlett presented on process mapping as a means to analyze workflows of different e-resource processes to help a library decide what is needed from an ERM. ${ }^{39}$ Troubleshooting access issues for discovery systems using a systematically arranged set of queries and tests, Carter and Traill believed the visual cues inherent with flowcharts provides the proper communication tool with training, documentation, and as a reference aid. ${ }^{40}$

\section{Method}

Along with writing complete documentation for the departmental wiki for the e-book acquisitions process, the authors decided to demonstrate the entire workflow using a flowchart visualization. Since they were holistically interested in the process (one visualization for all the types of e-book acquisition models in use at the authors' library), they initially intended to recreate the workflow identified in Beisler and Kurt's paper "E-Book Workflow from Inquiry to Access: Facing the Challenges to Implementing E-Book Access at the University of Nevada, Reno." ${ }^{\text {,41 }}$

As the authors examined Beisler and Kurt's paper and studied its workflow diagram, they noted that three possible acquisition paths for e-books were identified: 1. Database subscription or standing order; 2 . One-time purchase, no annual fees, and; 3. One-time purchase, with annual fees. ${ }^{42}$ Since the publication of their paper, more types of e-book acquisition emerged, some of which the authors use in their department. As a result, they could not mimic Beisler and Kurt's diagram for their purpose. Using Beisler and Kurt's "path" approach, the authors considered the types of e-book acquisition presently used at their library and identified the six following major types: 1. Firm order e-books; 2. Firm order e-book collections; 3. Approval order e-books; 4. Demand-driven e-books; 5 . Standing order e-books, and; 6 . Subscription e-book database.

The authors drafted procedural documentation on how each type of e-book acquisition is handled at their library. They used that documentation to create a visualization of each acquisition type, to "depict the roles of a variety of stakeholders who impact or act in the process. ${ }^{3 * 3}$ Finally, the authors merged the visualizations for each type of e-book acquisition into one large visualization to view the entirety of the acquisition process as a whole. They recorded the procedural documentation in a wiki on the web-based PBworks platform and created the visualizations of the process maps in the web-based software, Lucidchart. ${ }^{44}$ The following sections describe the format of the procedural documentation and the authors' decisions regarding how to create the process maps.

\section{Procedural Documentation}

All staff in the authors' Acquisitions and Collection Development Department were given user accounts for the PBworks wiki platform, and the agency to create/revise/ 


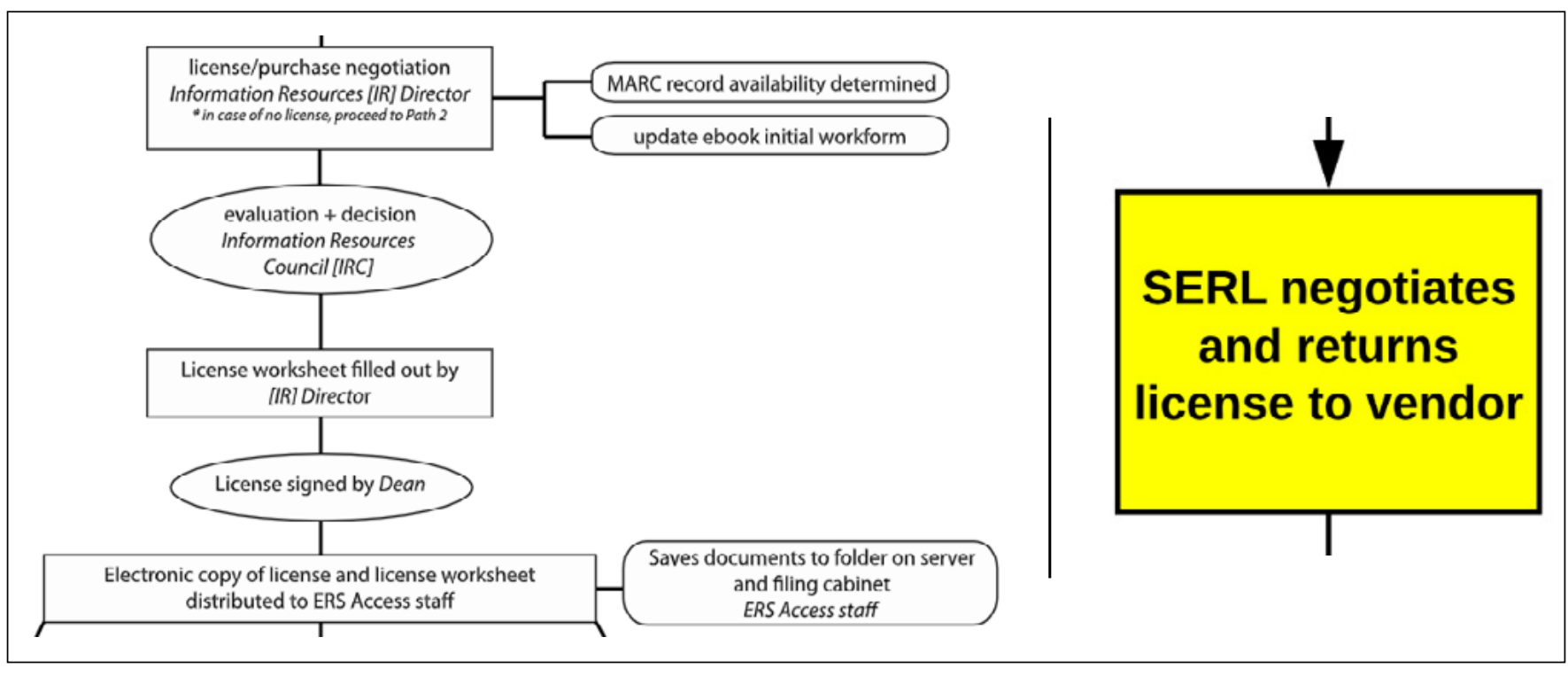

Figure 1. Level of Detail in Process Map

delete documentation for the procedures with which they are tasked. With the redesign of the departmental procedural manual, a template was created with four sections; one to introduce the procedure that links to a process map (the Description section), one for the detailed steps in the procedure (the Instructions section), one with a summarized list of tasks to check from the procedure (the Checklist section), and one listing procedures related to it in some way (the Follow-up section). A horizontal line marks the end of one section and the beginning of the next.

Here the authors describe the organization of the template in use for all of the e-book acquisition procedures. There are seven components to the Description section: introduction, purpose, staff involved, trigger point, frequency, required systems, and backups. The introduction states what procedure is being documented. The purpose states the procedure's rationale. The staff involved component lists the title of the staff person who performs the procedure. The trigger point notes what causes the procedure to take place. The frequency states how often the procedure occurs. The required systems component lists all systems required to complete the procedure. The backups component states the titles of two staff members who can perform the procedure if the person formally tasked is unavailable and how much acceptable time may pass before someone else has to perform the procedure. Below these is a link to a process map, with the specific parts of the procedure highlighted.

The Instructions section follows and contains detailed steps of the procedure with accompanying screenshots to help backups perform these tasks with confidence. The Checklist section follows and contains a summarized list of all tasks that should have been completed without the detail from the previous section. The last part of the template is the Follow-up section which lists links to any quality control procedures identified to ensure the procedure has been completed accurately and other procedures that are involved in the completion of the larger process. For the sake of completeness, the authors have written procedural documentation for each of the six major e-book acquisitions processes described in this paper. Each document is supported by a process map.

\section{Process Maps}

Early on in the development of their process maps, the authors had to decide how much text to display at each step. Keeping Mackinder's workflows comment that they "are and should be bigger-picture," the authors decided that their process maps would be limited to brief textual information at each of the steps, noting the person responsible for the step and a high-level summary of the work accomplished. ${ }^{45}$ The left portion of figure 1 is the part of Beisler and Kurt's model related to licensing. ${ }^{46}$ The right side shows how the authors have chosen to represent licensing using more brief text. Since each step in the process maps have a corresponding section in the procedure that details the work to be completed, the authors found that brief text in the process map is sufficient.

The authors also had to make some design choices at the outset to ensure that their workflows were visually consistent. For simplicity, they used only five shapes in their workflows. The Lucidchart software defines the names for these shapes. The authors used a terminator (capsule) 


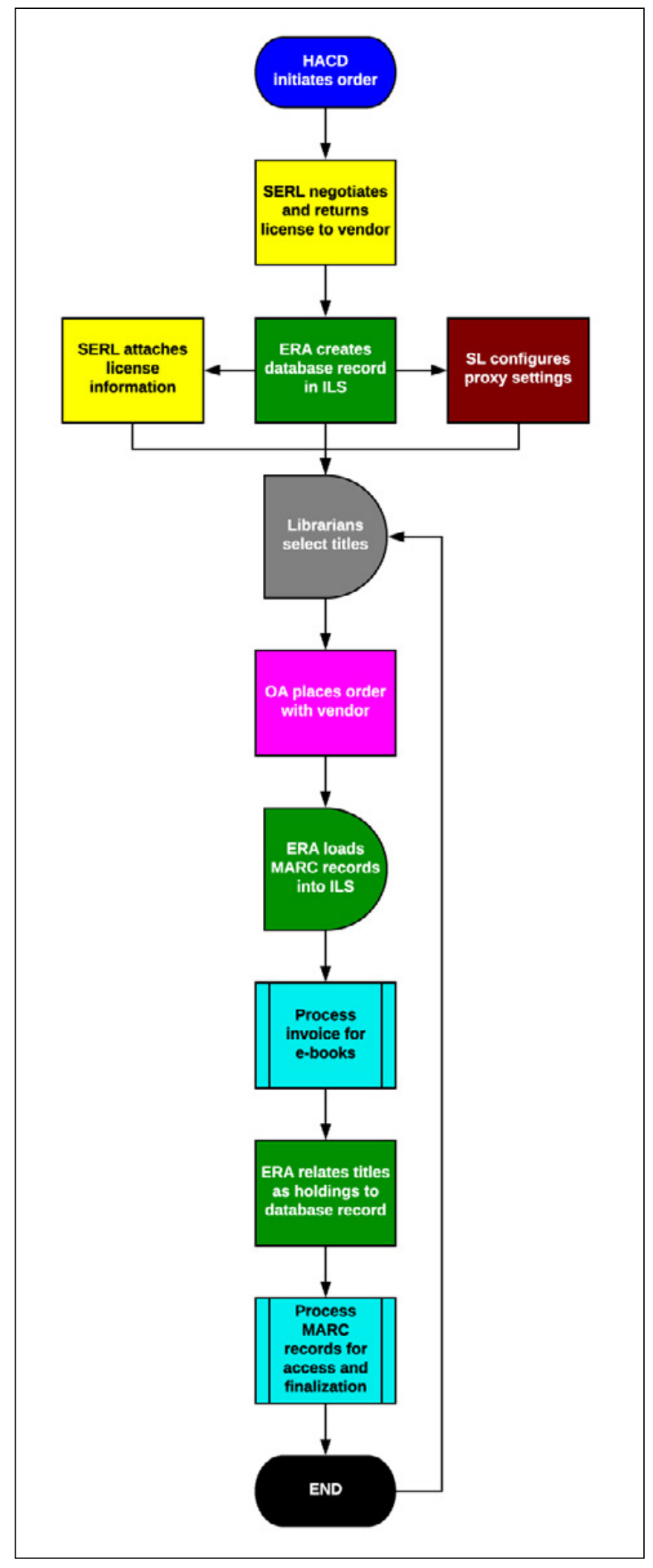

Figure 2. Process Map for Purchasing One-time, Single e-book Titles for the start and end steps in the workflow. They used a process box (simple rectangle) for an action. A predefined process box (simple rectangle with an additional bar on each side) was used to show an action that takes place but is not required to be completed for the workflow to move forward. They used a decision (diamond) when the staff person completing the process posed a question. Lastly, a delay (capsule cut in half) was used to signify when a procedure must pause due to an external factor on the process.

Each staff person involved in the procedure is represented in the workflow by a different color; the shape is filled with the color assigned for the steps in the procedure for which they are responsible for completing. These colors are another visual cue used to gauge how much of a workflow is completed by any number of staff. The authors included the initials of the job titles in the step. "Electronic Resources Assistant," for example, is represented in all workflows as ERA. There are seven abbreviated stakeholders represented in the following process maps: Collection Development Committee (CDC), Electronic Resources Assistant (ERA), Head of Acquisitions and Collection Development (HACD), Librarian for Collection Development and Evaluation (LCDE), Ordering Assistant (OA), Serials and Electronic Resources Librarian (SERL), and Systems Librarian (SL). While tasked with redesigning the wiki, the acquisitions librarian is not an active stakeholder in these workflows but provides consultation and support gained from previously holding the ERA position. With their design elements defined, and decisions regarding how much text to include at each step in the workflow, the authors created the workflows for their six major e-book acquisitions processes.

\section{Firm Order E-books}

The library has licenses with many publishers to purchase materials through a third-party ordering system. With this system, any selector may purchase single title e-books and charge the purchase to the academic funds that he or she manages. In the resulting process map (see figure 2), the authors describe the process for purchasing one-time, single e-book titles.

The shape at the top is a terminator and is indicated with the text "HACD initiates order." The HACD is shown in workflows as the color blue. From the initial step of initiating the order, the process moves to the next shape: a process box with the text "SERL negotiates and returns license to vendor." At the authors' institution, it is mandatory to have in place a counter-signed license agreement from a vendor or publisher before purchases are made. The SERL completes this process. Between these two shapes is a directional arrow showing which step follows the first one. From this second step, one is visually guided to the third 
shape: a process box with the text "ERA creates database record in ILS." The ERA creates a collection-level record in the ILS for the vendor or publisher as an organizing step. From this step, the workflow splits into three directions; the SERL attaches the terms and conditions of the license agreement to the collection-level record and the SL activates the collection in the proxy server configuration file. This enables resources to be accessed by off-campus users, and the librarians may begin purchasing e-books. Adjustments to the proxy server configuration can also occur after e-books are purchased if it is discovered to be incomplete. Because the selection process is intermittent and ongoing, this workflow step is visualized with the delay shape. Six staff/librarians are involved in the procedure shown by the process map for firm order e-book purchases.

\section{Approval Order E-books}

To enable the library to receive e-book content without the need for individual title selection, the HACD maintains an approval profile with a preferred vendor that automatically supplies e-books meeting predefined criteria in the profile.

The acquisition process for approval order e-books shares a workflow with firm order e-books (as visualized in figure 2), with the differences between the acquisition types noted in a detailed written procedure. Weekly title lists are provided by the approval vendor based on the predefined criteria, and this is currently limited to physics and chemistry and available through the vendor's ordering system. Unless an action is taken prior to the release of the next weekly approval list, these titles are automatically approved for order.

\section{Firm Order E-book Collections}

The library's CDC sometimes purchases a bundle of e-books from a publisher or aggregator, a decision usually predicated on desirable content that aligns with the library's collection. Since the purchase of a collection of e-books is costly, the decision to purchase is made at the committee level rather than by an individual selector.

The process for purchasing an e-book collection follows a similar workflow as individual e-books, with a few notable differences (as shown in figure 3). In this workflow, the CDC acts as the selector and individual librarians do not take action; the workflow represents this distinction because there are only five distinct staff noted. There is also a difference in how the order is placed because the SERL takes this action after negotiating the license with the vendor, unlike firm order e-books that are handled by the OA. Additionally, a single invoice for an e-book collection is processed before MARC records are loaded into the ILS, whereas processing occurs with firm order e-books each

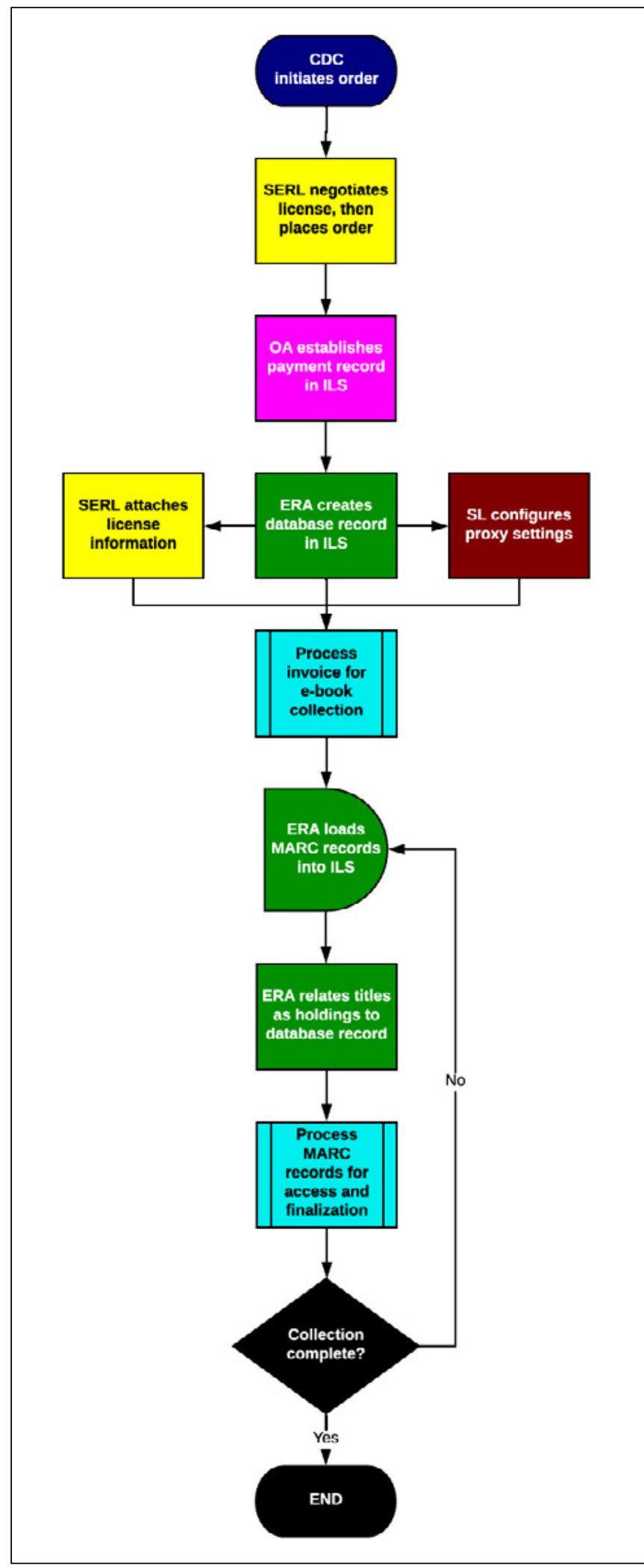

Figure 3. Process Map for Firm Order e-book Collections 
time an invoice is received and once the MARC records are loaded into the ILS. With single title e-book purchases, the content is available in a relatively short time after purchase; this may not be the case with an e-book collection. If all content has not yet been published, the procedure must pause. With this workflow, the ERA must check periodically to see if new titles have been added to the collection. Their MARC records are loaded as new titles are added. This workflow is only complete when all content in the collection has been published, with records loaded into the ILS and related to the database record, and quality control procedures completed.

\section{Subscription E-book Database}

To gain access to a constantly changing, continually updated e-book collection, the library has e-book database subscriptions. The CDC has chosen to pursue some e-book subscriptions to round out the collection and to provide a large number of e-books addressing multiple academic areas.

The process of acquiring an e-book database subscription follows a selection path most similar to a firm order e-book collection, with a few exceptions. MARC records are continually loaded and removed from the ILS. After the initial load of MARC records, access checking, and quality control measures (as shown in figure 4), this workflow temporarily halts. Monthly updates indicate which MARC records need to be removed from the collection and new ones added, and so the terminator (the step marked "END") leads back to the step in the workflow to prompt the ERA to bring the catalog up to date.

\section{Demand-Driven E-books}

The departmental heads of Acquisitions and Serials and Collection Development initiated a demand-driven acquisitions workflow in 2011, with a test of seven subject profiles in their preferred vendor system. The pilot test served the library's patrons well enough that a decision was made to continue the service, expanding it to all of their subject areas. In 2013, the demand-driven profile was refined to also include short-term loans to address one-time or low uses of that e-book content.

Users are instrumental to this workflow since they drive selection decisions for the collection. The use of discovery records in the ILS provides the patron with a means to discover a DDA title, and the available titles continually change based on the vendor supplied records. Much like the subscription e-book database, the MARC records in the ILS are in flux with additions and deletions until the use of a title results in a purchase. This workflow is based on a predefined trigger event, a patron purchase of content, or a short-term loan of content. Each trigger event spurs

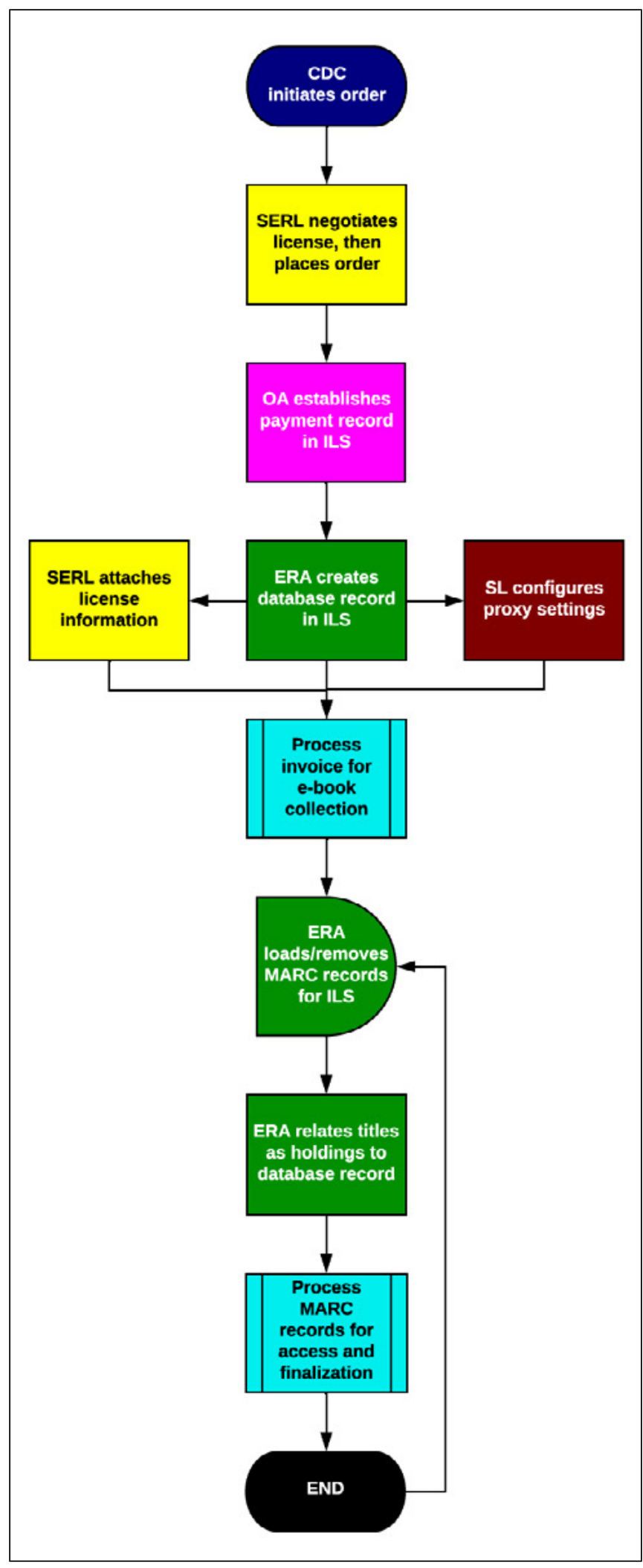

Figure 4. Process Map for Subscription e-book Database 


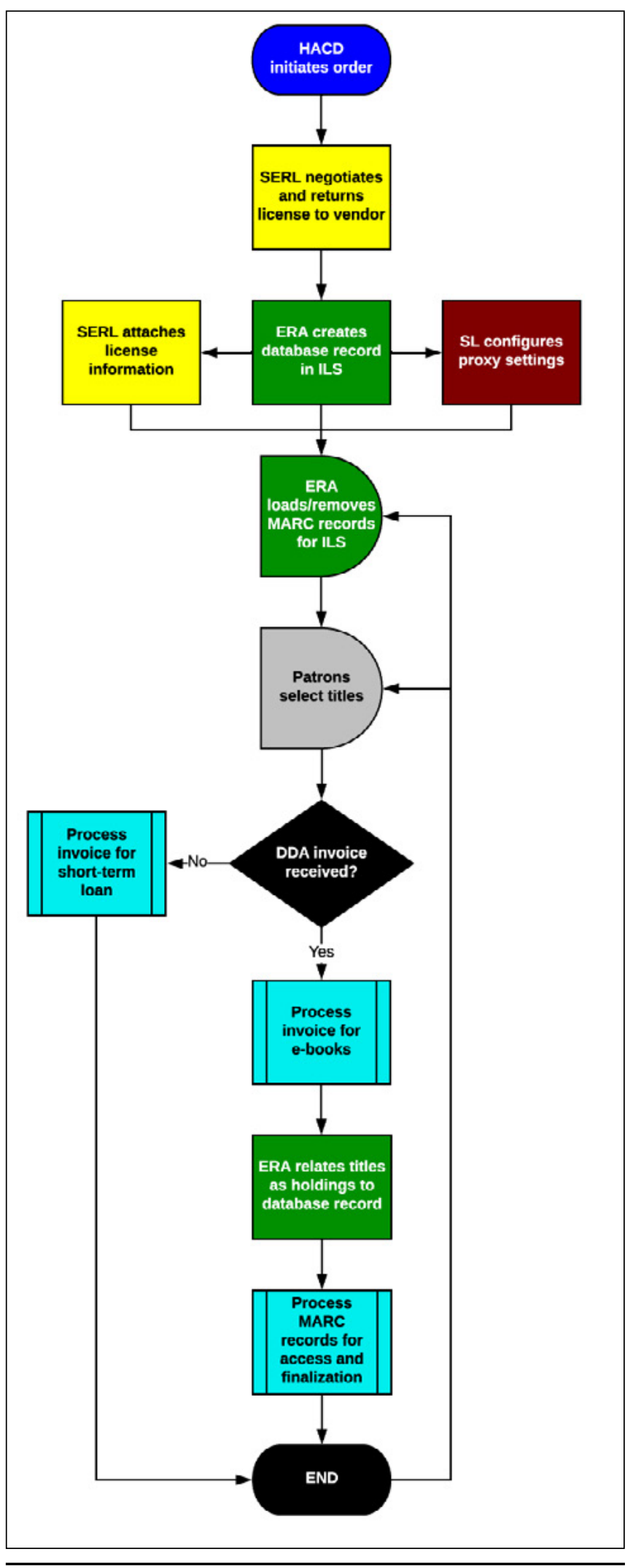

Figure 5. Process Map for Demand-driven e-books the production of an invoice, the processing of which is addressed in the workflow (shown in figure 5).

\section{Standing Order E-books}

As selectors choose books to add to the collection, they may discover that titles belong to a monographic series and decide to start a standing order because the theme identifying them as a group contributes value to the overall collection. With this workflow, the selector will make a request to include the series of titles (with content in the series yet to be published) in the collection. The LCDE will examine the series and approve/deny its inclusion. Some factors influencing this decision include its relevance to the library's collection and the financial impact to the budget. If the LCDE approves the inclusion of the series, the SERL will pursue the negotiation of a license agreement, unless it is part of an existing license, and then the order and initial records are entered into the ILS by the OA (as shown in figure 6). After the initial set up of the series in the ILS, MARC records and invoices are received and processed as new volumes in the series are published. What differentiates a standing order e-book from the other acquisition types is that it may not follow or include all the steps outlined in the other e-book processes.

\section{A Merged Workflow: A Holistic Look at the E-book Purchasing Process}

The process map that merges the six e-book acquisition workflows provides a holistic view of how the processes relate to and diverge from one another. Each individual process map is represented by the following italicized abbreviations at the bottom of each shape (as shown in figure 7): Firm Order E-books (FO), Approval Order E-books (AO), Firm Order E-book Collections (FEC), Subscription E-book Database (SUB), Demand-Driven E-books (DDA), and Standing Order E-books (STO). Processes that occur in all of the workflows are represented as ALL. All workflows converge in the Merged E-book Acquisition Workflow process map, as shown in the center of figure 7, where three actions take place: "SERL attaches license information"; "ERA creates database record in ILS"; and "SL configures proxy setting." The second convergence of processes occurs towards the bottom of the process map where two actions take place: "ERA relates titles as holdings to database record" and "Process MARC records for access and finalization."

All the process maps begin with initiation of an order, and three unique stakeholders perform this action: the HACD, librarian, and CDC. On the merged process map there are three starting points: "HACD initiates order" 


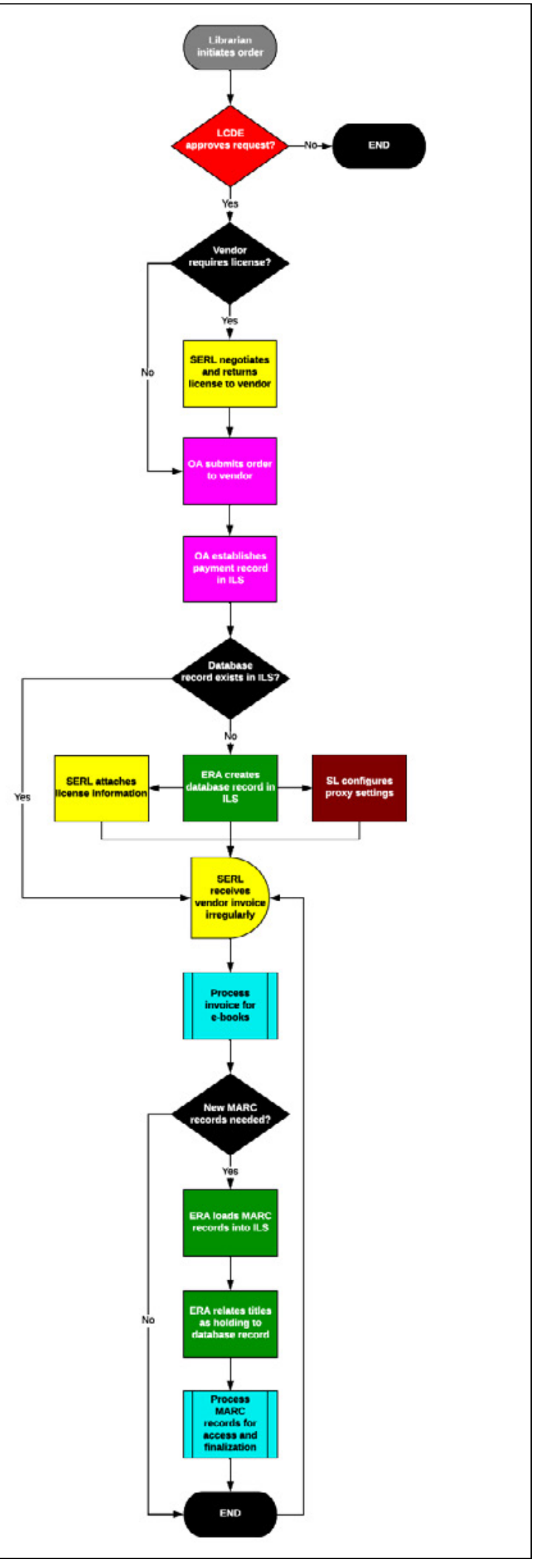

Figure 6. Process Map for Standing Order e-books begins the AO, DDA, and FO workflow; "Librarian initiates order" begins the STO workflow; and "CDC initiates order" begins the FEC and SUB workflow. Each workflow on the merged process map temporarily ends as each one goes back to a delayed action to continue, looping indefinitely; MARC records are continually being added and removed from the ILS in the SUB workflow, while new titles are consistently selected and ordered in the other workflows, with the exception of the FEC workflow. This workflow ends when all MARC records from the collection of titles are provided.

\section{Analysis}

The authors' intention in defining e-book acquisition processes for each model in a step-by-step manner is to ensure that the individuals charged with completing the process work in a consistent, thorough manner, and to help them gain an understanding of the entire process. Sharing the entire process with all relevant individuals has contributed to an appreciation for the work of others in the department and a better understanding of the process. Documenting procedures has eliminated the issue illustrated in Dowdy and Raeford, "Effective communication ... was driven by email and human memory"; anyone in the department can now refer to a procedure on the wiki with ease, rather than relying on a person or email. ${ }^{47}$ Beyond the documentation aspect, the authors believe that merging the steps into a visual process map has assisted in the understanding of the whole process. As Copeland et al. note, the visual representation makes "it a good starting point for conversations about procedures." ${ }^{348}$

As the authors documented procedures and created process maps, they met frequently with staff involved in the larger task to gather feedback and to better describe how the process proceeded from one person to the next, and sought efficiencies. This process of writing, visualizing, and discussing has helped streamline all the e-book acquisitions processes. The authors found that if they defined a shortcut for one process, it was likely that it could be used in other processes.

Using a wiki for the documentation has proven to be important for the writing process since the wiki architecture saves previous versions of documents; the history of the development of these procedures is saved as part of the system itself. The wiki also permits the authors to track the dates of changes to documents and indicates who made the changes. Creating a document template has helped the department to organize how documentation is written and enables them to quickly find desired sections of any document, based on the structure they have defined.

Using online software like Lucidchart has been 


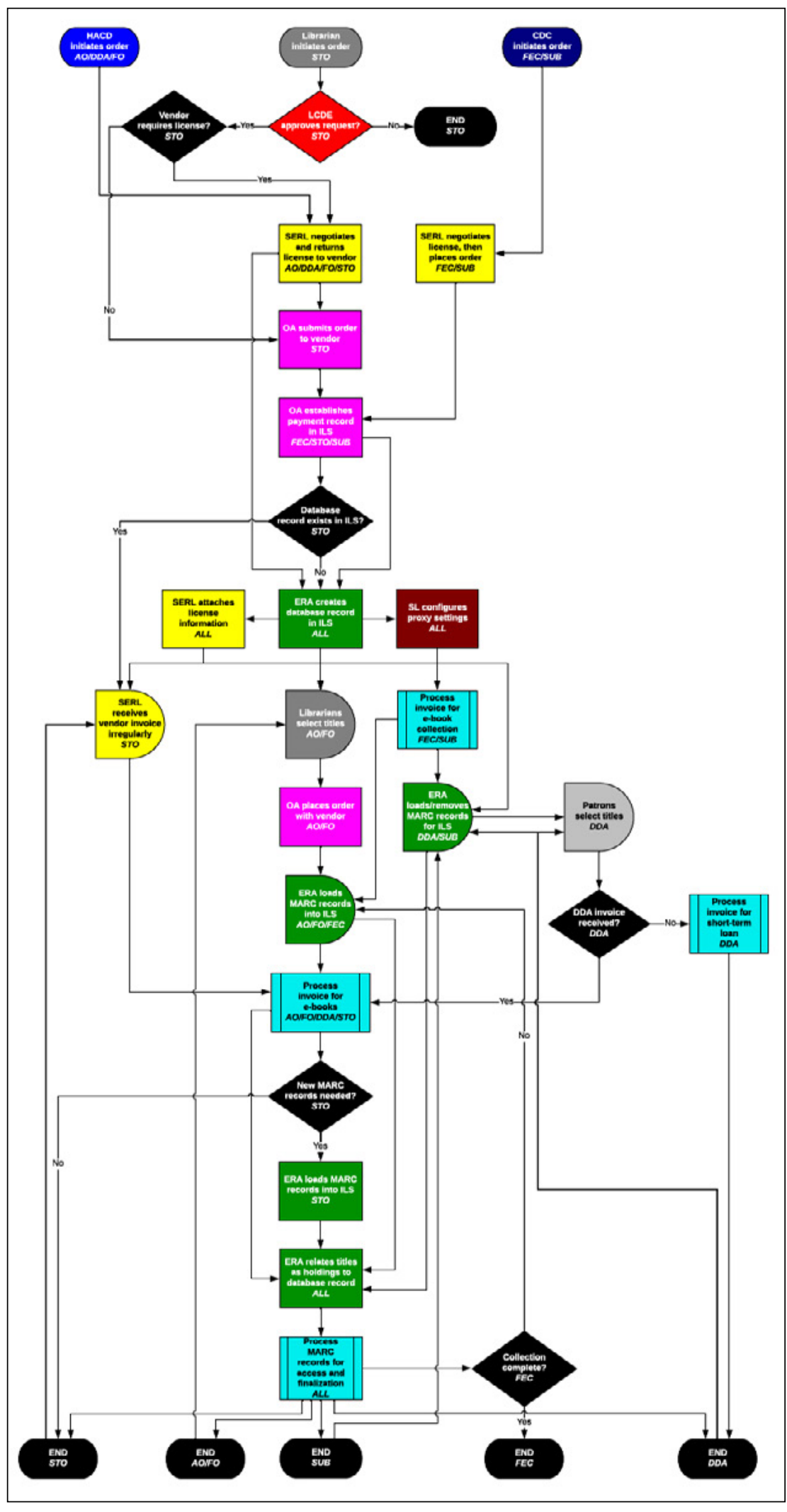

Figure 7. Process Map Merging the Six e-book Acquisition Workflows advantageous for the authors because of its ease of use. Having defined for themselves a style guide (which shapes to use, which font style and size, and which colors to use for which staff member), the authors can easily change existing visualizations as procedures evolve.

\section{Limitations and Future Research}

When the authors initially began to document procedures, the main objective was to record them quickly to preserve the knowledge of the existing staff. When they neared completion, the next goal was to expand what was drafted so that any staff member assigned as a backup for a procedure could confidently perform it as needed. A process map provides a visual roadmap to connect multiple interrelated procedures, with each written procedure being for a single person, into a larger process involving multiple people. The sections of a digital manual containing separate written procedures for an individual's use are now interlinked in a diagram showing a series of actions taking place to complete a complex process.

The authors consulted the professional literature for a single acquisitions workflow process for e-books and realized none exist because there are too many variables, including, but not limited to, how departments are organized and the number of staff employed. Although a specific ILS is not identified in the process maps, the use of a different one could affect the sequence of steps in comparison since systems have different capabilities and limitations. While it is possible for other libraries to use process maps constructed for the authors' library as a starting point to document their own e-book acquisition workflow models, the authors cannot address its scalability.

Related to scalability is how documenting and creating process maps can be sustained at the authors' institution. They found the process to be necessary but time consuming. Developing process maps in addition to the documentation was another component that requires a fair amount of time. The authors learned that once drafted, it is important to discuss the 
maps with stakeholder staff members to confirm or suggest changes. Given their current staffing structure, the authors may choose to continue process mapping without stakeholders to minimize the impact workflow documentation can require of a person's time. They began their process by listing all the department's procedures that needed to be documented, and selecting what was most critical to be fully developed; in this case, it was e-book acquisitions. The authors will likely return to that list and continue to address procedures essential to the department's mission.

Though much attention in the literature is devoted to troubleshooting e-resources (summarized well by Carter and Traill), troubleshooting largely happens as a maintenance issue, external to the usual acquisitions process. ${ }^{49}$ There may be initial quality concerns to consider as MARC records for e-books are loaded or accessed (matters such as missing or incorrect URLs, proxy issues, or catalog record errors) and the authors consider those as part of the set-up process completed by their ERA. Therefore, they have chosen to not include troubleshooting in their documentation or process maps in this paper.

\section{Conclusion}

The authors recorded an e-book acquisition workflow from a holistic perspective. They wove their case study of work undertaken at a mid-sized library in higher education into the wider literature in the areas of workflow and process mapping, highlighting the changes currently taking place in the landscape of e-acquisitions. An important takeaway from this process is the inclusion of stakeholder staff in devising the procedures they will then follow. Using this approach, the authors divided potentially complicated workflows into manageable chunks and think as a team about how the pieces fit together. By approaching e-book workflows from this perspective, the authors hope to provide their own staff with a sense of the big picture-how all of their individual processes contribute to the whole of the acquisitions process.

\section{References}

1. Melissa De Fino and Mei Ling Lo, "New Roads for PatronDriven E-books: Collection Development and Technical Services Implications of a Patron-Driven Acquisitions Pilot at Rutgers," Journal of Electronic Resources Librarianship 23, no. 4 (2011): 332, https://doi.org/10.1080/194112 6X.2011.627043.

2. Lisa Mackinder, "The Seemingly Endless Challenge: Workflows," The Serials Librarian 67, no. 2 (2014): 159, https:// doi.org/10.1080/0361526X.2014.940481.

3. Mackinder, "The Seemingly Endless Challenge," 159.

4. Mackinder, "The Seemingly Endless Challenge," 162.

5. Amalia Beisler and Lisa Kurt, "E-book Workflow from Inquiry to Access: Facing the Challenges to Implementing E-book Access at the University of Nevada, Reno," Collaborative Librarianship 4, no. 3 (2012): 103-07, https://digitalcom mons.du.edu/collaborativelibrarianship/vol4/iss3/3/.

6. Magadalini Vasileiou, Jennifer Rowley, and Richard Hartley, "The E-book Management Framework: The Management of E-books in Academic Libraries and Its Challenges," Library \& Information Science Research 34, no. 4 (2012): 283, https://doi.org/10.1016/j.lisr.2012.06.005.

7. Vasileiou, Rowley, and Hartley, "The E-book Management Framework," 283-89.

8. Elsa K. Anderson, "Electronic Resource Management Systems: a Workflow Approach," Library Technology Reports 50, no. 3 (2014): 11-22, http://doi.org/10.5860/ ltr.50n3.
9. Mackinder, "The Seemingly Endless Challenge," 161.

10. Laura Tull, Janet Crum, and C. Rockelle Strader, "Integrating and Streamlining Electronic Resources Workflows via Innovative's Electronic Resource Management," The Serials Librarian 47, no. 4 (2005): 103-24, https://doi.org/10.1300 /J123v47n04_11.

11. Lenore England, Li Fu, and Stephen Miller, "Checklist Manifesto for Electronic Resources: Getting Ready for the Fiscal Year and Beyond," Journal of Electronic Resources Librarianship, 23, no. 4 (2011): 307-26, https://doi.org/10.1080/194 1126X.2011.627041.

12. Beverly Dowdy and Rosalyn Raeford, "Electronic Resources Workflow: Design, Analysis and Technologies for an Overdue Solution," Serials Review 40, no. 3 (2014): 175-87, https://doi.org/10.1080/00987913.2014.950040.

13. Kelly Smith, "Managing Electronic Resource Workflows Using Ticketing System Software," Serials Review, 42, no. 1 (2016): 59-64, https://doi.org/10.1080/00987913.2015.1137674.

14. Mingyu Chen, Misu Kim, and Debbie Montgomery, "Ebook Record Management at the University of Texas at Dallas," Technical Services Quarterly 33, no. 3 (2016): 251-67, https://doi.org/10.1080/07317131.2016.1169781.

15. Beisler and Kurt, "E-Book Workflow from Inquiry to Access," 97, 105.

16. Kari Schmidt, "ERM Ideas and Innovations," Journal of Electronic Resources Librarianship 24, no. 4 (2012): 301-5, https://doi.org/10.1080/1941126X.2012.732835. 
17. De Fino and Lo, "New Roads for Patron-Driven E-Books," 327-38.

18. Daniel C. Draper, "Managing Patron-Driven Acquisitions (PDA) Records in a Multiple Model Environment," Technical Services Quarterly 30, no. 2 (2013): 153-65, https://doi .org/10.1080/07317131.2013.759813.

19. Kay Downey, “Technical Services Workflow for Book JobberMediated Demand Driven ebook Acquisitions," Technical Services Quarterly 31, no. 1 (2014): 1-12, https://doi.org/10 .1080/07317131.2014.844617.

20. Wendolyn C. Vermeer, "Evolving Technical Services Workflows in a Demand-Driven Acquisitions Pilot," The Serials Librarian 69, no. 3-4 (2015): 298-309, https://doi.org/10.10 80/0361526X.2015.1118719.

21. Jill Emery, "Beginning to See the Light: Developing a Discourse for Electronic Resource Management," The Serials Librarian 47, no. 4 (2005): 137-47, https://doi.org/10.1300 /J123v47n04_13.

22. Annie $\mathrm{Wu}$ and Anne M. Mitchell, "Mass Management of E-Book Catalog Records: Approaches, Challenges, and Solutions," Library Resources \& Technical Services 54, no. 3 (2010): 164-74, http://doi.org/10.5860/lrts.54n3.164.

23. Stacie Traill, "Quality Issues in Vendor-Provided E-Monograph Records," Library Resources \& Technical Services 57, no. 4 (2013): 213-26, http://doi.org/10.5860//rts.57n4.213.

24. Ariel K. Turner, "Establishing Batch Processes for E-books," Technical Services Quarterly 33, no. 2 (2016): 121-30, https://doi.org/10.1080/07317131.2016.1134996.

25. Vasileiou, Rowley, and Hartley, "The E-Book Management Framework," 290.

26. Valeria Hodge, Maribeth Manoff, and Gail Watson, "Providing Access to E-Books and E-Book Collections: Struggles and Solutions," The Serials Librarian 64, no. 1-4 (2013): 200-05, https://doi.org/10.1080/0361526X.2013.760411.

27. Hodge, Manoff, and Watson, "Providing Access to E-Books and E-Book Collections," 203-4.

28. Jacquie Samples and Ciara Healy, "Making It Look Easy: Maintaining the Magic of Access," Serials Review 40, no. 2 (2014): 105-17, https://doi.org/10.1080/00987913.2014.929483.

29. Emery, "Beginning to See the Light," 139-43.

30. Vasileiou, Rowley, and Hartley, "The E-Book Management Framework," 290.

31. Cynthia A. Watkins, "Using Flowcharts to Streamline Document Delivery Services in an Academic Library," Journal of Interlibrary Loan, Document Delivery \& Information Supply 10, no. 2 (2000): 79-83, https://doi.org/10.1300/J110 v10n02_07.

32. Sarah Barbrow and Megan Hartline, "Process Mapping as Organizational Assessment in Academic Libraries,"
Performance Measurement \& Metrics 16, no. 1 (2015): 34-35, https://doi.org/10.1108/PMM-11-2014-0040.

33. Watkins, "Using Flowcharts to Streamline Document Delivery Services," 77-88.

34. Daryl C. Youngman, "Process Flow Analysis in Academic Libraries," Technical Services Quarterly 24, no. 1 (2006): 37-44, https://doi.org/10.1300/J124v24n01_03.

35. Paoshan W. Yue and Rick Anderson, "Capturing Electronic Journals Management in a Flowchart," The Serials Librarian 51, no. 3-4 (2007): 101-18, https://doi.org/10.1300/J123 v51n03_07.

36. Jessie L. Copeland et al., "Workflow Challenges: Does Technology Dictate Workflow?” The Serials Librarian 56, no. 1-4 (2009):268-69,https://doi.org/10.1080/03615260802690777.

37. Dina Tbaishat, "Using Business Process Modelling to Examine Academic Library Activities for Periodicals," Library Management 31, no. 7 (2010): 480-93, https://doi .org/10.1108/01435121011071184.

38. Valerie Prilop, R. Niccole Westbrook, and Elizabeth M. German, "Collaborative Project Development in the Creation of an Interdepartmental Digitization Workflow," Collaborative Librarianship 4, no. 2 (2012): 60-66, https://digitalcom mons.du.edu/collaborativelibrarianship/vol4/iss2/4.

39. Alexandra Hamlett, "Keeping up with the Flow: Electronic Resource Workflow and Analysis," The Serials Librarian 70, no. 1-4 (2016): 168-74, https://doi.org/10.1080/036152 6X.2016.1159434.

40. Sunshine Carter and Stacie Traill, "Essential Skills and Knowledge for Troubleshooting E-resources Access Issues in a Web-Scale Discovery Environment," Journal of Electronic Resources Librarianship 29, no. 1 (2017): 11-13, https://doi.org/10.1080/1941126X.2017.1270096.

41. Beisler and Kurt, "E-Book Workflow from Inquiry to Access," 106.

42. Beisler and Kurt, "E-Book Workflow from Inquiry to Access," 105.

43. Barbrow and Hartline, "Process Mapping as Organizational Assessment in Academic Libraries,” 35.

44. The PBworks wiki is available via http://www.pbworks.com. The Lucidchart flowchart software is available via http:// www.lucidchart.com.

45. Mackinder, "The Seemingly Endless Challenge," 159.

46. Beisler and Kurt, "E-Book Workflow from Inquiry to Access," 106.

47. Dowdy and Raeford, "Electronic Resources Workflow," 177. 48. Copeland et al., "Workflow Challenges," 269.

49. Carter and Traill, "Essential Skills and Knowledge for Troubleshooting E-Resources," 1-15. 